\title{
Factors Influencing Movement of the Manila Dunes and Its Impact on Establishing Non-Native Species
}

\author{
Buddhika Madurapperuma ${ }^{1,2, *}$, James Lamping ${ }^{1}$, Michael McDermott ${ }^{3}$, Brian Murphy ${ }^{2}$, \\ Jeremy McFarland ${ }^{4}$, Kristy Deyoung ${ }^{1}$, Colleen Smith ${ }^{1}$, Sam MacAdam ${ }^{1}$, Sierra Monroe ${ }^{1}$, \\ Lucila Corro $^{2}$, Shayne Magstadt ${ }^{2}$, John Dellysse ${ }^{5}$ and Solveig Mitchell ${ }^{3}$ \\ 1 Department of Forestry and Wildland Resources, Humboldt State University, Arcata, CA 95521, USA; \\ jel436@humboldt.edu (J.L.); kld601@humboldt.edu (K.D.); cls33@humboldt.edu (C.S.); \\ swm112@humboldt.edu (S.M.); slm1065@humboldt.edu (S.M.) \\ 2 Department of Environmental Science and Management, Humboldt State University, Arcata, CA 95521, USA; \\ bpm213@humboldt.edu (B.M.); lmc148@humboldt.edu (L.C.); sm639@humboldt.edu (S.M.) \\ 3 Department of Geography, Humboldt State University, Arcata, CA 95521, USA; \\ mlm940@humboldt.edu (M.M.); sem620@humboldt.edu (S.M.) \\ 4 Department of Anthropology, Humboldt State University, Arcata, CA 95521, USA; jdm850@humboldt.edu \\ 5 Army Corps of Engineers, San Rafael, CA 94102, USA; jed386@humboldt.edu \\ * Correspondence: bdm280@humboldt.edu; Tel.: +1-707-826-3620
}

Received: 22 March 2020; Accepted: 6 May 2020; Published: 12 May 2020

\begin{abstract}
Unmanned aerial vehicles (UAVs) are being widely used to monitor microtopographic and vegetation changes in coastal habitats using remote sensing techniques. Sand dune habitats are vital ecosystems along the North coast of Humboldt County in California. This study was conducted at the Manila Dunes, west of the Humboldt Coastal Nature Center, in Manila, California. Various factors influence dune movements, including vegetative stabilization and the creation of social trails. The purpose of this paper is to understand the dune movements in relation to social vs. established trails, vegetation density, topography, and also, mapping invasive vs. native species in the Mal-le'l Dunes area of the Humboldt Bay National Wildlife Refuge. A DJI Mavic Pro multicopter small unmanned aerial vehicle (UAV) was used to fly a 22.5-acre plot of the Manila Dunes. The images from this flight were used to create an orthomosaic image using a photogrammetry process (Structure-from-Motion (SfM)). From our analysis, the installation of trails lessened the impact of dune movements. Social trails digitized within the study site were found to have more local movements than the established trails when compared to movements across the entire site. We compared two methods of classification, viz., the object-based feature extraction method and a pixel-based supervised maximum likelihood classification method, in order to identify the best way to classify dune vegetation. In conclusion, this study is useful for providing baseline dune movement information that can aid in informing how trail and infrastructure constructions can be impacted in land management or in areas with dynamic communities of flora and fauna.
\end{abstract}

Keywords: UAV; KAP; Manila Dunes; erosion; invasive species; social trails

\section{Introduction}

Dune ecosystems are complex and dynamic systems that are influenced by geo-morphological changes, anthropogenic activities, and climatic vulnerabilities. Mapping coastal areas is challenging with moderate-resolution Landsat imagery because of the complexity of the landforms and the dynamic microtopographical features of the habitat [1]. Unmanned aerial vehicles (UAV) have become a popular and cost-effective remote-sensing technology, composed of aerial platforms capable of 
carrying small-sized and lightweight sensors [2]. With the advent of commercially available unmanned aerial vehicles (UAVs), it is feasible to collect high spatial and temporal-resolution imagery of an area of interest. Currently, UAV-acquired imagery is widely used for coastal habitat mapping [3], dune morphological changes [4], beach erosion [5], and vegetation communities [6].

Conversely, UAV data collection is not always possible. This is true in instances where the cost of UAV equipment is prohibitive or when poor weather and high tree density will not permit it or, also, permitting issues from landowners. Kite aerial photography (KAP) is a trustworthy alternative for coastal mapping due to the low cost, high spatial resolution (for example, 4-cm resolution imagery with a 10-megapixel camera [7]), limited regulation, and easy flying during high wind velocities [7]. Kite aerial photography (KAP) was originally developed in 1887 [8]. Since then, KAP has been used for aerial surveys for many different purposes and for many years. In recent years, KAP has been adapted to monitor unique coastal habitats [7].

Sand dunes are common and distinctive ecosystems that occur along the shorelines of our Pacific Ocean. They provide specialized habitats for rare and endangered species, as well as protect beaches from future erosion. The Manila Dunes is an ever-changing landscape within Humboldt County, CA. The dunes are valued by both the community and local scientists, which makes it a great fit to study potential hazards, including erosion and deposition, while also implementing a positive game plan for continuing the longevity of this location. The Friends of the Dunes Land Trust (FOD) is a nonprofit organization that has been dedicated to engaging the community in the conservation of coastal environments since 1982. The land trust manages the approximately 118-acre Humboldt Coastal Nature Center (HCNC) along the coast of Northern California (https: //www.friendsofthedunes.org/humboldtcoastalnaturecenter). The HCNC public recreation area is characterized by its unique coastal grassland and sand dune ecosystem. Here, coastal dune habitats are highly dynamic and constantly changing as a result of human-created social trails, climate and climate-induced variability such as the sea level rise, and coastal erosion [3,9]. Some characteristics of social trails are: often stem off of main, established trails, not likely to be created along steep slopes, paths that visitors have created on their own through repetitive foot traffic, and are more likely to follow paths of least resistance, as they are often used as shortcuts [9,10].

This ecosystem is fragile and is frequently impacted by anthropogenic disturbances, including social trails, as well as climate change-related disturbances. Social trails are defined as informal visitor-created trails or visually discernible pathways, which become unplanned and unmaintained trail networks [11]. For instance, a social trail could be a vector of invasive species spread [9,10]. Too many social trails in an area fragment the native species habitats, which allows for the propagation and spread of invasive plant species [12]. Climate changes also drive invasive species occurrences and movements, which then impact the distribution and composition of flora in coastal dune grass habitats [13]. The social trails have disturbed dune mat habitats via the trampling of rare plant communities, spreading of invasive species, and disturbing bee-nesting colonies [9,14,15].

Wind, sediment supply, and the dynamic topology of the surrounding environment determine dune morphology [16]. Not only do movements have the ability to cycle nutrients, but they can also create niches for unique specialist species and help facilitate a diverse dynamic ecological community [15]. Wind direction and magnitude are two primary contributing factors in sand migration [17]. Surface resistance either by vegetation or the moisture of sand affects these processes. When wind collides with vegetation, it slows down due to near-surface drag, which, in turn, triggers sediment deposition as the reduction in wind speed reduces the sediment-holding capacity [18]. Moisture of the sand is also a factor of sand movements, which causes grains to become looser or aggregated, contributing to sand resistance or destabilization [17].

A huge factor in determining a lost dune habitat is understanding dune stabilization. Dune stabilization is the phenomenon where the loose sand dunes begin to become more rigid and stationary, instead of dynamic. This removes a niche for many native species and prevents them from playing important environmental roles within the ecosystem, which further destabilizes the biome. This Pacific 
Northwest dune habitat, located in Humboldt County, is prone to a variety of invasive plant species. The most debilitating species is European beach grass (Ammophila arenaria), although the FOD has been working to restore the area back to native dune species by removing this grass [3]. In addition, ice plant (Carpobrotus chilensis) and yellow bush lupin (Lupinus arboreus) are also notorious for dune stabilization and have been found at the FOD study site $[3,10]$. To counteract this influx of plants, the Friends of the Dunes spend considerable efforts in controlling the influence and spread of these invasive species.

This study sought to understand if and how derived vegetation density, erosion potential, social trail distribution, and invasive species presences influence dune movements and stabilization within the HCNC area. The factors we examined were: the presence and estimated density of vegetation, social and established trails, classified erosion potential, and invasive species presences. We hypothesized that vegetative species, especially those with deep rooting systems, may have a stabilizing effect on the dunes, causing a reduction of movements in those habitats. Furthermore, we hypothesized that social trails may be an influencing factor in increased dune movements. While established trails (the FOD opened the main trail for public access in 2007 [19]) are likely placed in low points to decrease dune height loss, social trails may have a significant impact on dune destabilization and erosion, thus increasing the height loss. The other goal of the study is to map site-specific invasive/native species occurrences in terms of anthropogenic influences and microtopographical characteristics of dune habitats.

\section{Materials and Methods}

\subsection{Study Area}

This study focused on a small area within the Humboldt Coastal Nature Center in Humboldt County, CA. This area is surrounded by Manila Dunes to the north and the Manila Dunes to the south (Figure 1). The Manila Dunes consist of 444 acres of public land featuring dune habitats characterized by dune, coastal forest, and wetland communities. Although not currently present, the native grasses of this site are American dune grass (Leymus mollis) and beach bluegrass (Poa macrantha). According to vegetation surveys in this area, buckwheat (Fagopyrum esculentum), coyote brush (Baccharis pilularis), dune goldenrod (Solidago spathulata), European beach grass (Ammophila arenaria), European sea rocket (Cakile maritima), and ice plant (Carpobrotus edulis) dominate as dune mats in the study area [20]. This study utilized UAV and KAP data to monitor vegetation health, invasive species movements, social trails, and dune movements through the analysis of high-resolution aerial images collected using commercial-grade UAV and KAP $[3,7,9]$. 


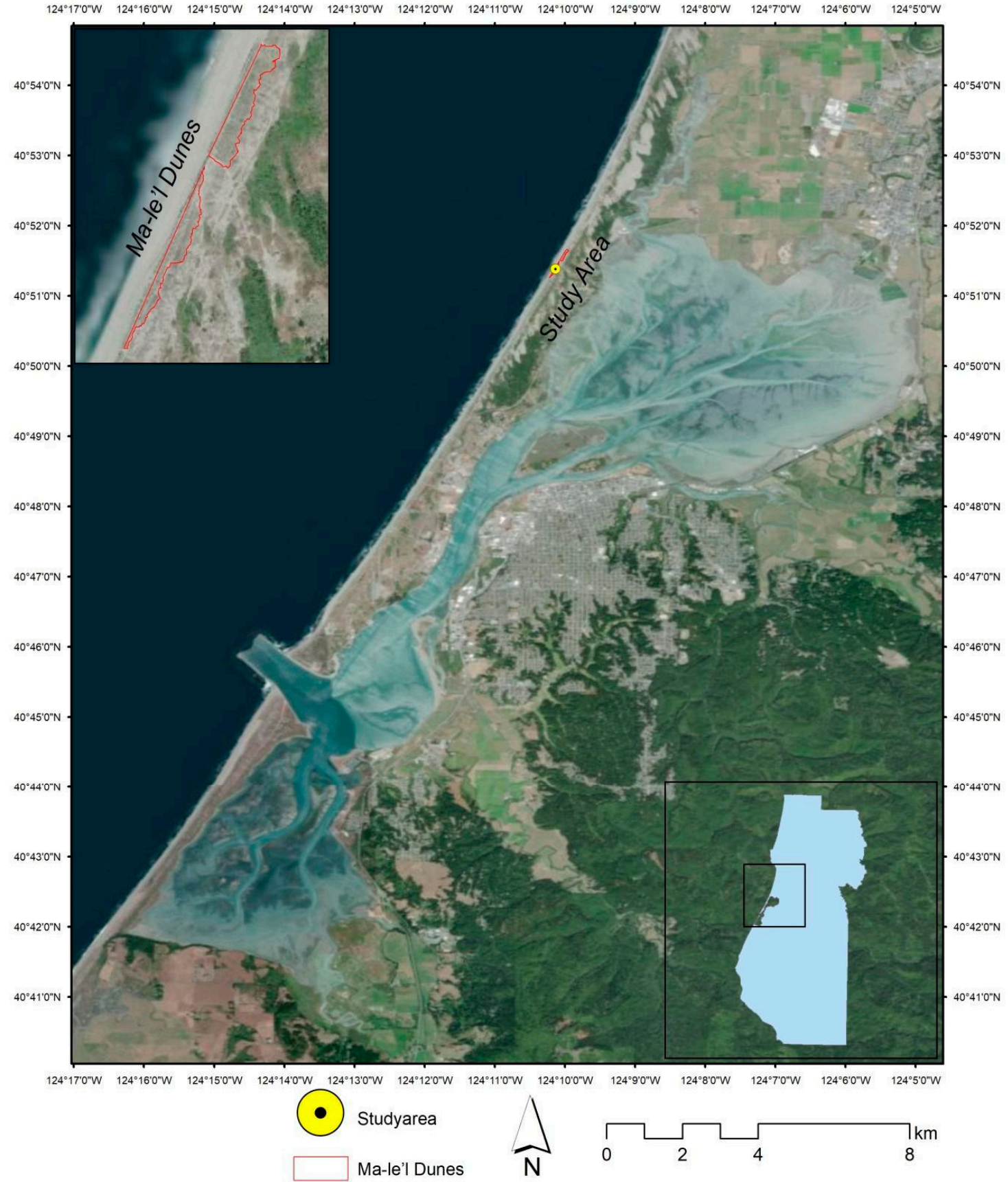

Figure 1. Locator map of the study area at the Friends of the Dunes in Manila near Humboldt Bay Area, CA.

\subsection{UAV/KAP Data Acquisition}

The aerial images (UAV and KAP) were acquired on September 14th, 2018 between 12:30 p.m. to 1:00 p.m. On this date, the tidal height measured at the Fields Landing, Humboldt Bay, CA (9418723) site by a National Oceanic and Atmospheric Administration (NOAA) North Spit tidal gauge ranged from 1.1-1.7 $\mathrm{m}$ with respect to the mean lower low water (MLLW) datum (https: //tidesandcurrents.noaa.gov). Vegetation cover in the dune mat community is low, and the species composition comprises approximately 30 native plant species, and their adaptive capabilities are diverse $[19,21]$.

A mission plan was created within the region of interest (ROI) using DJI GS Pro@ software Airdata UAV, Inc. El Dorado Hills, CA, USA) prior to flying the UAV (DJI Mavic Pro@ (Nanshan 
District, Shenzhen, China) at the FOD. Aerial photographs were collected at a height of 42 meters over a 22.5-acre plot using a DJI Mavic Pro multicopter (DJI, Shenzhen, China) equipped with a 12-megapixel RGB camera (DJI FC220 model with 4.73 focal length).

Prior to the UAV flight, ten ground control points (GCPs) were placed across the plot, and coordinates were recorded using a Trimble GeoExplorer 6000 series GPS with a Tempest external antenna (Figure 2). GCP coordinates were post-processed through differential GPS (DGPS) correction using Trimble Pathfinder Office ${ }^{\complement}$ Ver. 5.9 software (Trimble Inc.) and obtained 7-cm accuracy coordinates. The 427 images collected from the UAV flight were used to create an orthomosaic image from SfM in Agisoft PhotoScan Pro version 1.4.4 (Agisoft LLC, St. Petersburg, Russia) with a ground resolution of $5 \mathrm{~cm}$. The root mean square reprojection error for the mosaic image was 1.6 pixels.
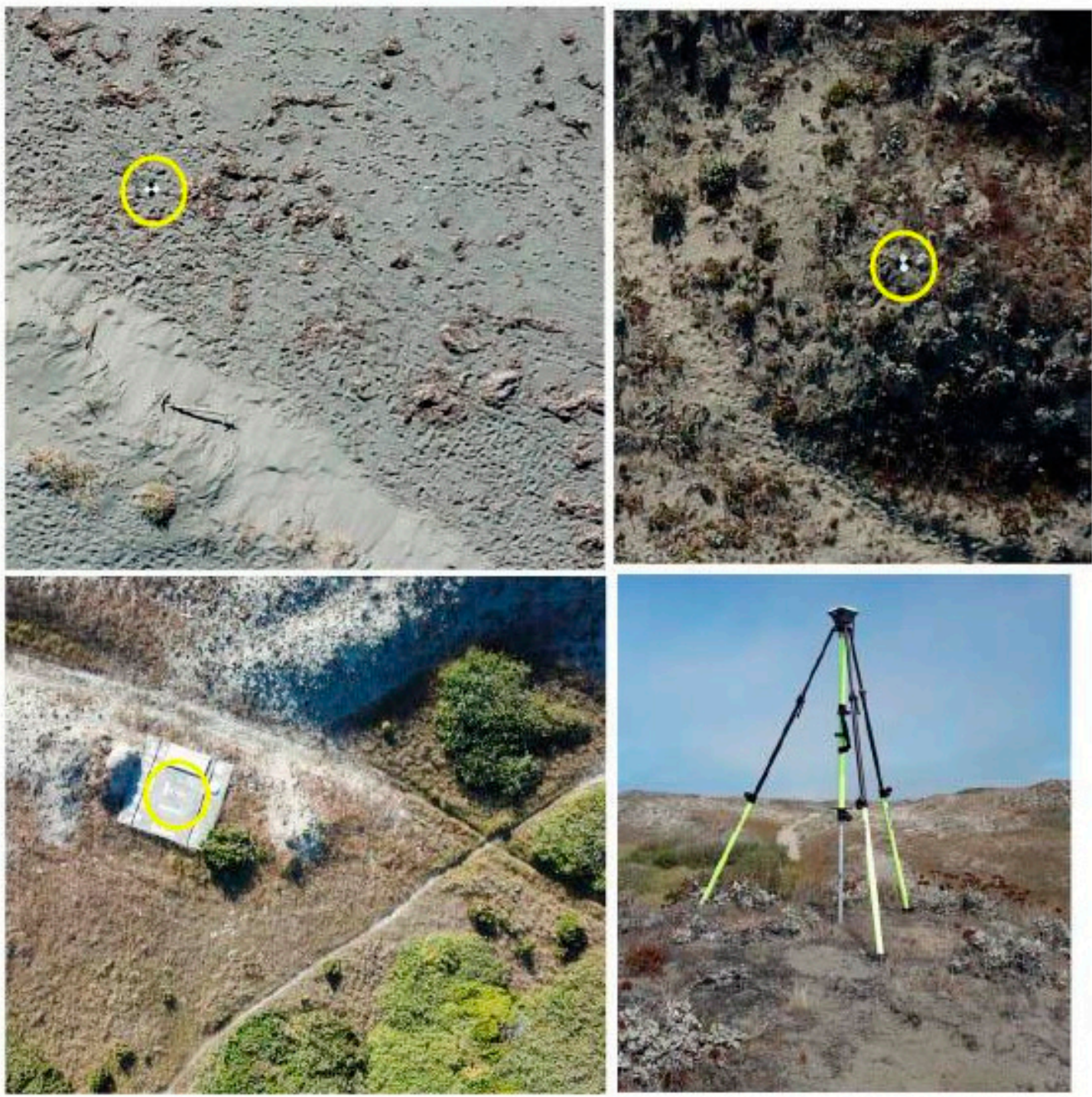

Figure 2. Setting up the ground control points (GCP) spaced across the Friends of the Dunes study site. The yellow circles show the tiles for acquiring the GCP and the Trimble GeoExplorer used to collect the GPS data.

A kite aerial photography (KAP) platform was created using two lightweight automatic cameras with dual-bandpass Red-NIR filters, a Picavet stabilizing rig [22], and a Parafoil kite. The kite was flown 20 minutes under 15-20 mph wind speeds. Kite aerial images were collected using two downwards-facing Canon Power Shot A490 digital cameras with 10 megapixels (one color and one near-infrared) at approximately 30-m altitude (Figure 2). In addition, we flew a second flight with 
a Parafoil kite that was attached to a GoPro camera to a Picavet stabilizing rig to acquire geotagged photos. For the purpose of evaluating the effectiveness of the vegetation mapping, ground control points for plant identification were taken within the KAP ROI using a Garmin GPS. The 396 KAP images were used to create an orthomosaic image from Structure-from-motion (SfM) in Agisoft PhotoScan with a ground resolution of $2.3 \mathrm{~cm}$. These orthomosaic images were used to create a digital surface model (DSM) using the Agisoft PhotoScan ${ }^{\complement}$ software.

\subsection{Dune Movement from UAV Data}

In this study, two UAV images (September 14th, 2018, 5-cm, and September 27th 2019, 5.4-cm resolution) were used to calculate the dune movements around the major sensitive locations of the study area with the expert knowledge of the FOD staff. We used Matrice 100 UAV to acquire multispectral data at the FOD in 2019. Using the image-to-image technique, the UAV image of 2019 was used to perform the geometric correction of the 2018 UAV image using the ground control points acquired from real-time kinematic (RTK) GPS with an accuracy of $7 \mathrm{~cm}$. The images coregistered with the root mean square error (RMSE) ranged from 0.2 to 0.5 pixels for both images. The UAV 2019 image was resized to the equivalent of the same pixel size $(5 \mathrm{~cm})$ of the UAV 2018. Dense point cloud data was created using mosaic UAV imageries using Agisoft PhotoScan ${ }^{\complement}$ software. The dense point cloud data was then used to build the DSM for both 2018 and 2019. We adopt the Ghadiry et al. [23] method to detect the elevation change between 2018 to 2019 by subtracting the digital surface models. The 2018 DSM was used to derive the percent slope, which was the generic input to create the decision tree model, displaying dune movement erosion and deposition areas.

\subsubsection{Datasets Created to Assess Dune Movements}

To determine the amount of dune movements from digital elevation model (DEMs), we calculated the elevation changes of the established and social trails. Of the digitized trails, an established and a social trail (a proximity to each other at the start and the end point of the trail) at the backdune were selected to determine the elevation changes over a year. Then, polyline-to-point conversions were made using a conversion toolbox, namely "generate points along lines". Next, points between 10-m spaces for both social and established trails were selected to extract elevation values from the 2018 and 2019 DEMs using the "extract multiple values to a point" in ArcMap ${ }^{\complement}$ 10.6.1 (Redlands, CA, USA). The spatial resolution for the DEMs was $0.12 \mathrm{~m}$.

A vegetation density model was created using a density interpolation algorithm function in ArcMap $^{\circledR}$ 10.6.1. First, the high-resolution orthoimagery was used to collect training point data through a visual check to differentiate vegetation from sand, shadow, and water. A raster-to-point function was performed on the classified raster, which converted all pixels containing vegetation into points. The density of these points was calculated using a density interpolation function. Density mapping shows where points or lines are condensed within a given area. The inverse distance weighted (IDW) interpolation method was used to estimate across any surface to show where the density lies (e.g., vegetation density) using the ArcMap. The resulting raster was then classified to 18 meaningful classes, such as 1 for less, 11 for moderate, and 18 for denser vegetation and the image symbolized using stretched type as the standard deviation (Figure 3).

In order to approximate the influence of the wind-on-dune movements, wind speed and directional data was obtained from NASA's MERRA-2 (Modern-Era Retrospective analysis for Research and Applications, Version 2) web portal (https://gmao.gsfc.nasa.gov/reanalysis/MERRA-2/data_access/). We observed 12 MERRA-2 images from 01-01-2018 to 31-12-2018 to find the wind direction. In addition, we used a Kestrel 3000 pocket weather station and compass to find the wind speed and wind direction, respectively. 


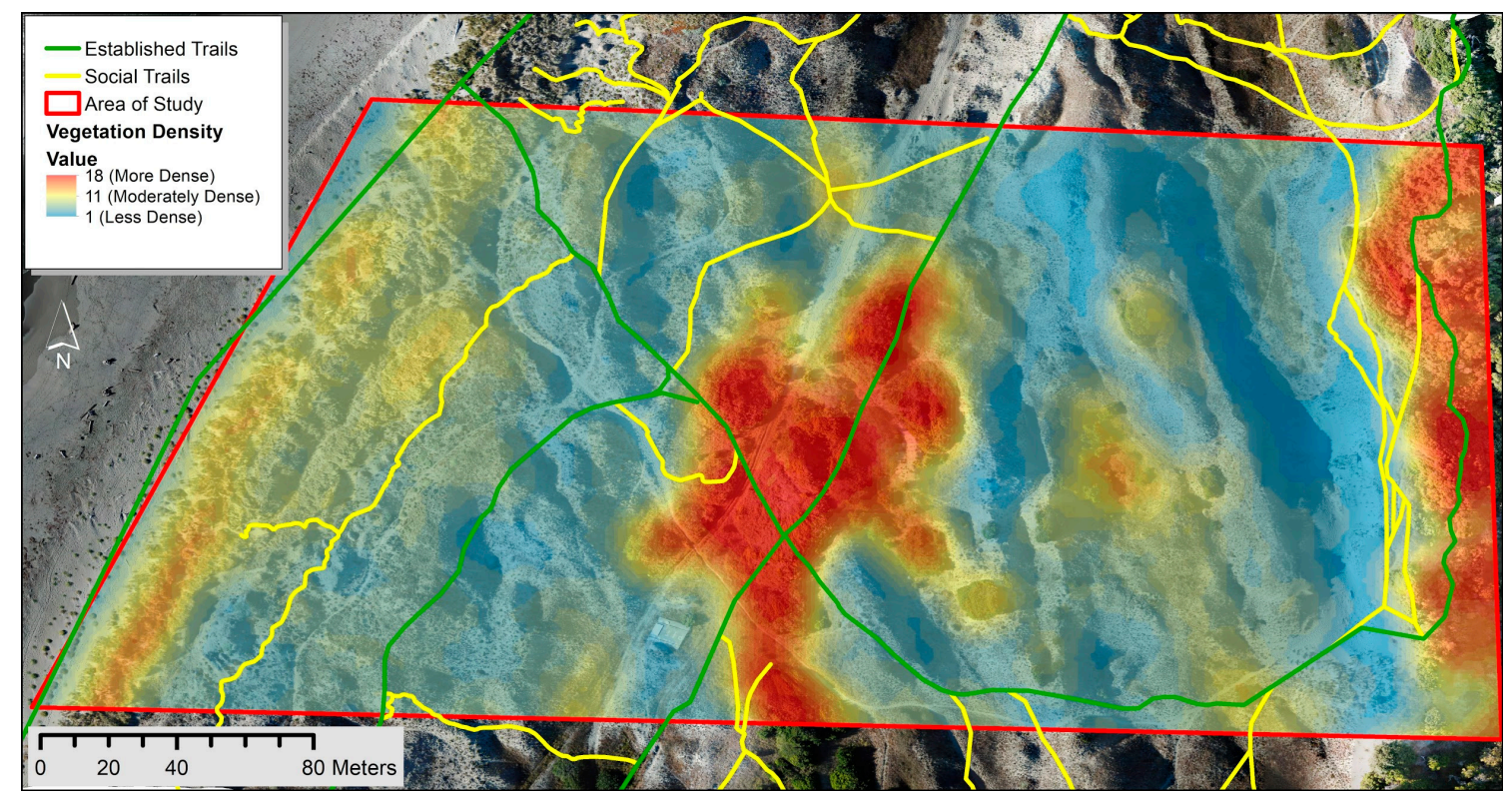

Figure 3. Vegetation density within the study site overlaid with both established and social trails digitized through unmanned aerial vehicle (UAV) imagery.

\subsubsection{Erosion and Deposition Decision Tree}

A decision tree is a statistical approach for developing a rule base for most important variables to delineate eroded and depositional areas of the dune habitats. It was created in ENVI ${ }^{\circledR}$ Classic 5.4 (Harris Geospatial Solutions, Boulder, CO, USA) utilizing the DSM and the vegetation density raster (Figure 4). The decision tree was structured so that all terminal nodes were factors that had influence over the dune movements. First, the decision tree model began with distinguishing areas containing vegetation and areas lacking vegetation. The vegetated pixels were given their own class. The non-vegetated pixels were sent down the tree where the pixels with a slope value greater than $30 \%$ (steep slope) were removed. This value was selected because $30 \%$ is the angle of repose for sand [24]. Pagán et al. [5] reported that the landslide of the dunes was experienced at a 30\% slope, which we selected as a threshold, assuming an angle of any sand pile face with a slope greater than $30 \%$ will collapse. The pixels that had a slope below the angle of repose were sent to the next branch of the tree, where vegetation density was considered. Areas that had density values greater than 11 (representing moderately dense vegetation) were isolated as a terminal node. This dense vegetation would act as a wind barrier, and the roots would stabilize the sand. The remaining pixels were then divided between areas that faced the wind and areas that did not. Wind direction data was found to have predominantly north and northwest winds for the summer months, with some southern winds occurring in the winter months. There was a strong offshore flow that may have had more influence over the area of interest than the data obtained from the MERRA-2. These wind direction values were calculated by creating an aspect calculation that isolated the west and north-facing areas. The north and west-facing slopes were then classified as being areas of erosion, and the south and east-facing slopes were classified as being areas of deposition. 


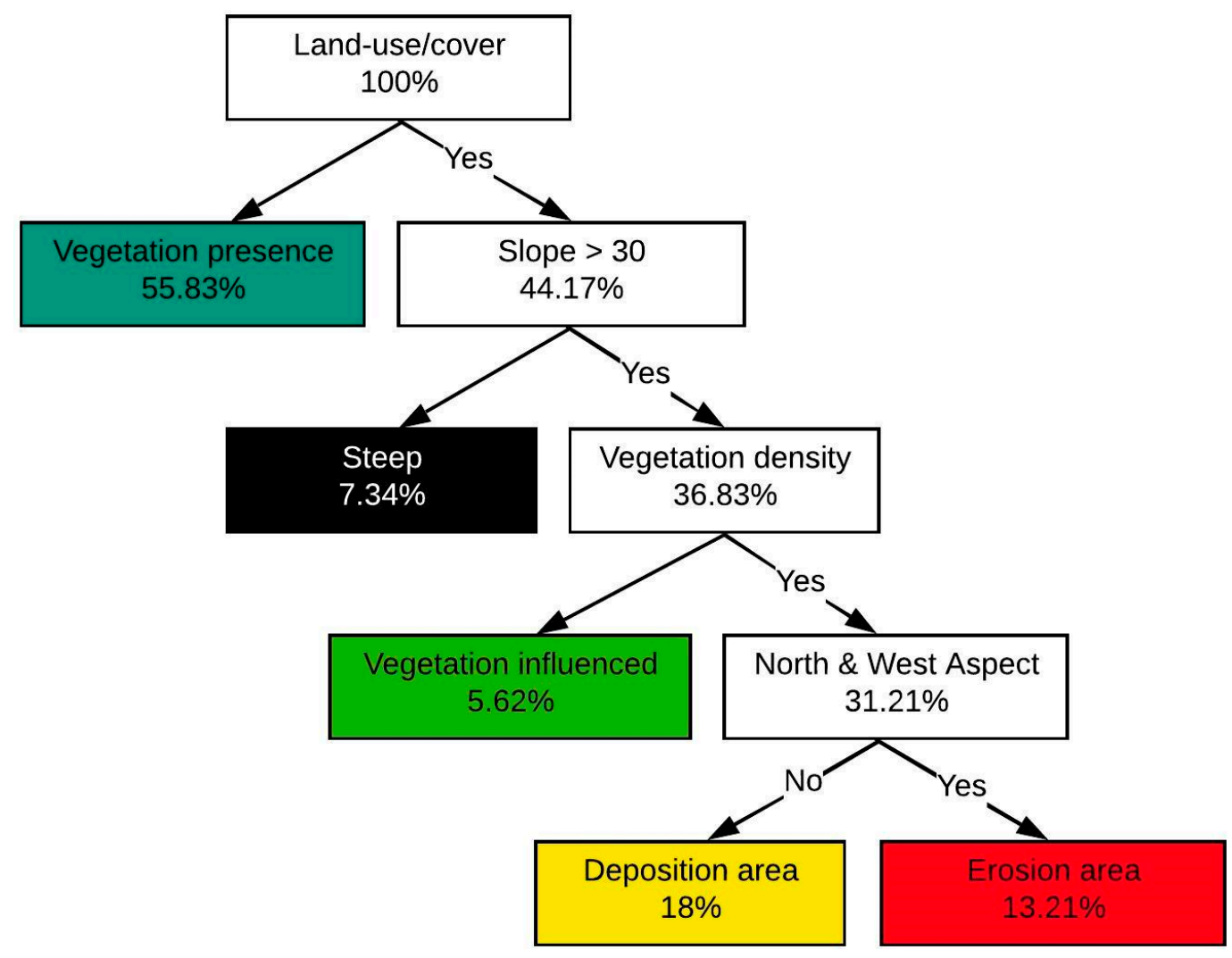

Figure 4. Outline of the decision tree diagram to display the deposition and erosion areas of the study area at the Friends of the Dunes. The color codes in the terminal node match with Figure 6.

The decision tree model was validated by comparing the areas of erosion and areas of deposition with observed movement values calculated by subtracting the two digital surface models (DSM derived from UAV imagery). Each class was exported from the decision tree raster and vectorized to calculate zonal statistics from the elevation difference raster.

\subsection{Image Classification for Invasive/Native Species}

We used KAP data for image classification for invasive and native species due to high spatial $(2.3 \mathrm{~cm})$ and spectral (four bands, RGB and NIR) resolutions. In addition, we used supervised and object-based feature extraction techniques to classify invasive/native species with the improvement of classifications using a texture analysis.

\subsubsection{Supervised Classification}

Agisoft PhotoScan was used to detect the feature points in each RGB and NIR bands when creating the orthomosaic images. Then, we composited RGB and NIR bands, resulting in four band combinations. The images were acquired within a clear sky day and low altitude to minimize the atmospheric effects. Due to limitations on the metadata for the KAP imagery, we had to rely on digital numbers $(\mathrm{DN})$ instead of reflection values for our analysis. When no preprocessing tasks are implemented, it is more reliable to analyze the vegetation index (VI) using NIR and IR. However, we had to rely on the normalized difference vegetation index (NDVI) due to the limitation on the IR band for the analysis. Then NDVI was incorporated for the texture analysis, to improve the vegetation classification. Using the "Raster Calculator" tool in ArcMap, the individual Red and NIR bands were brought in and used to calculate the NDVI with the following formula:

$$
\mathrm{NDVI}=(\mathrm{NIR}-\mathrm{RED}) /(\mathrm{NIR}+\mathrm{RED})
$$


By incorporating both a spectral and object-based approach for classifying, the classification is ultimately improved and error minimized. The "focal statistics" tool was then used to calculate both the mean and standard deviation of the NDVI raster. Before attempting the classification, the final step in creating the raster for the texture analysis was to composite all of the bands together [25]. The "composite bands" tool was used to combine the original RGB/NIR orthoimage, the NDVI mean, and the NDVI standard deviation into a single raster and clip to the extent where the NIR data was available. The new composite image was utilized in the pixel-based supervised classification and for the object-based feature extraction classification. As Madurapperuma et al. [3] revealed from their habitat mapping of the Ma-le'l Dunes study, a supervised classification works well with a large area, while feature extraction works well within a subplot.

For the supervised classification, training sample areas were created using geotagged photos taken from a GoPro Camera and visually comparing the sites using the high-resolution orthomosaic image. The ArcMap tool, namely "training sample manager", was used to train the program on a few specific vegetation and land cover types. Training samples were broken down into native and nonnative vegetation, wood, sand, and shadow classification types to generate a signature file of the sample areas. Using the training sample signature file, the "maximum likelihood classification" tool was used twice, to first classify vegetation based on just the RGB orthoimage and then ran again using the newly created NDVI texture composite orthoimage. The two output classification images that were created were then color-coded and compared to determine which method classified the invasive vegetation best.

We randomly created points across the subplot of the study area to make an accuracy assessment. We tested the accuracy for 13 classes, including native/invasive species (i.e., European Beach grass) and land-use/cover classes (i.e., sand, wood, etc.). A total of 130 points (10 points for each class) for the NIR/RGB composite image and 160 points for RGB image were used for the accuracy assessment.

\subsubsection{Feature Extraction}

To reduce the processing time of the feature extraction method, ArcMap ${ }^{\complement}$ was used to divide the study area into three equal sections, which were then further broken down into smaller study areas and used as the inputs for the feature extraction tool in ENVI ${ }^{\circledR}$ Classic 5.4 (Harris Geospatial Solutions, Boulder, CO, USA). An "example-based feature extraction" method was used as the specific type of feature extraction. After selecting one of the smaller ROIs for the feature extraction, we set our scale level for both segmentation and merge. These levels ranged dependent upon the chosen ROI (values ranged from 45-70 for segmentation and 50-80 for merge) and dictated a pixel's relationship to its neighboring pixels. Bands 1, 2, 3, and 6 from the composite image, representing red, blue, green, and NIR, respectively, were used for the analysis. After solidifying these settings, pixels were grouped together. These groups were then selected as classes representing their ground cover type. We utilized the ground control points of the chosen land-use/cover and species as training data to select classes for the feature extraction. The classified feature classes were native and invasive species (i.e., coyote brush, beach grass, ice plant, etc.) and land cover classes such as wood, sand, and other vegetation. All outputs were saved as vector files and as raster files ending in .dat.

To reconstruct the image, the ROI vector files were opened in ArcMap ${ }^{\complement}$ 10.5.1 and joined together using the "update" tool. Any extra or overlapping lines were cleaned up and attempted to be projected into a NAD 1983 UTM Zone 10 N coordinate system.

\section{Results}

This study incorporates the use of consumer-grade technology to study dune movements. The first part of the results presents dune movements in relation to sand deposition and erosion, and the second part gives the nonnative plant distribution within the dune ecosystem. 


\subsection{Dune Movement Estimates}

We created a DSM from the dense point cloud data for both 2018 and 2019 UAV imagery using Agisoft PhotoScan. Comparing the absolute value of the differences in the two DSMs (Earth's surface including objects on it) emphasized the shifts in dune movements over a year. While most of the area of interest did not have significant differences in elevation, the largest amount of change can be seen on the north-eastern-facing slopes that are not directly exposed to wind from the ocean (Figure 5). From this data, we can determine that where we find trails within the dunes, we generally see less sand movement. Our results are plausible, seeing as the social trails are often formed in similarly low points along the landscape as the established trials.

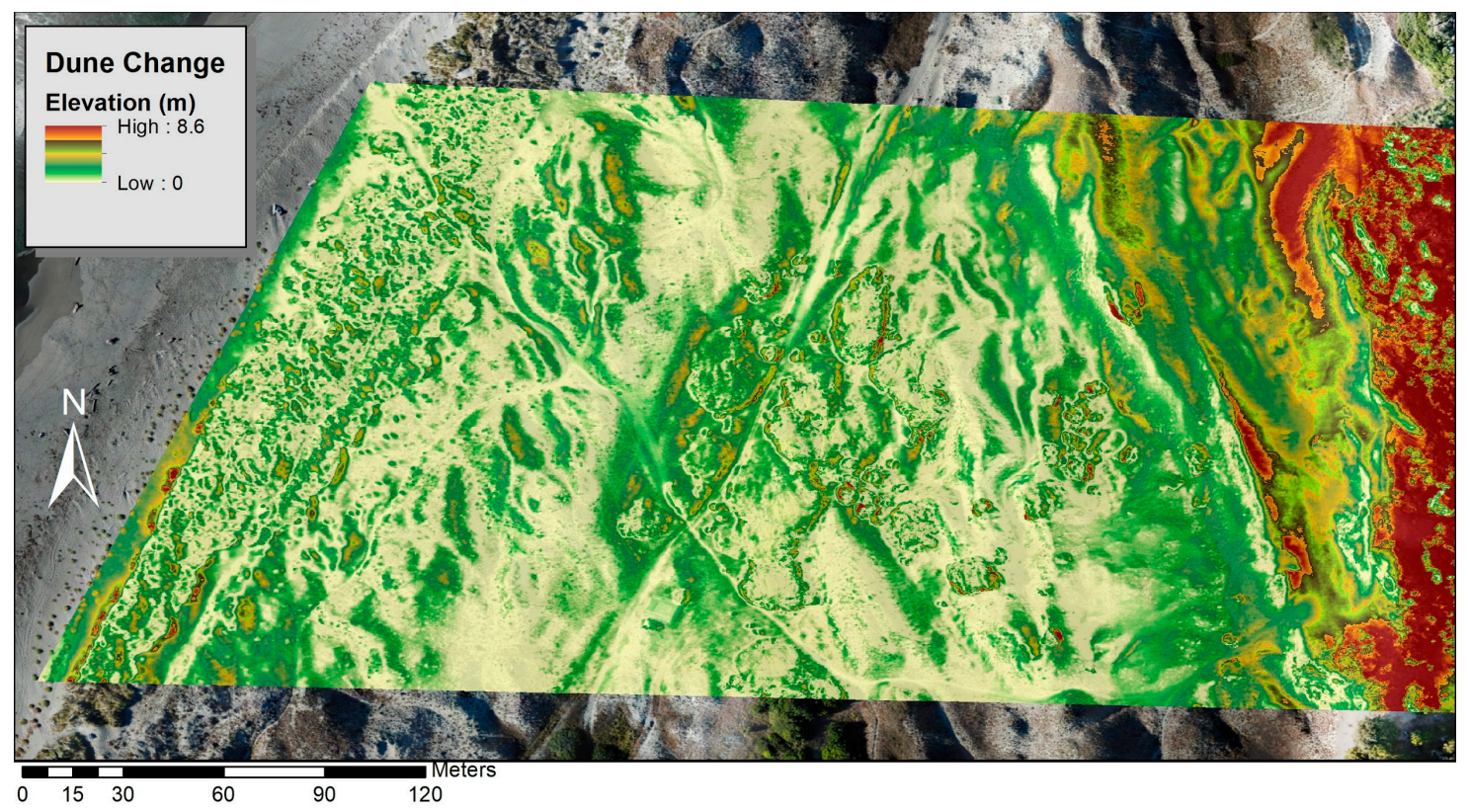

Figure 5. Map showing the differences in the two digital surface models (DSMs) (2019 UAV-derived DSM and 2018 UAV-derived DSM) emphasizing the shifts in dune movements in a year.

A pairwise comparison of the elevation changes between 2018 and 2019 along the established and social trails is given in Figure 6. Generally, established trails are located on comparatively high elevated ridges, while users created social trails attempting to take shortcuts from low elevated areas, and some points connect to the established trails (Figure 6c). The average elevation difference between two trails is more or less similar (i.e., established trails $1.03 \pm 0.45$ and social trails $1.02 \pm 0.22$ ). 
(a) • $2018 \Delta 2019 \diamond$ Elevation Difference

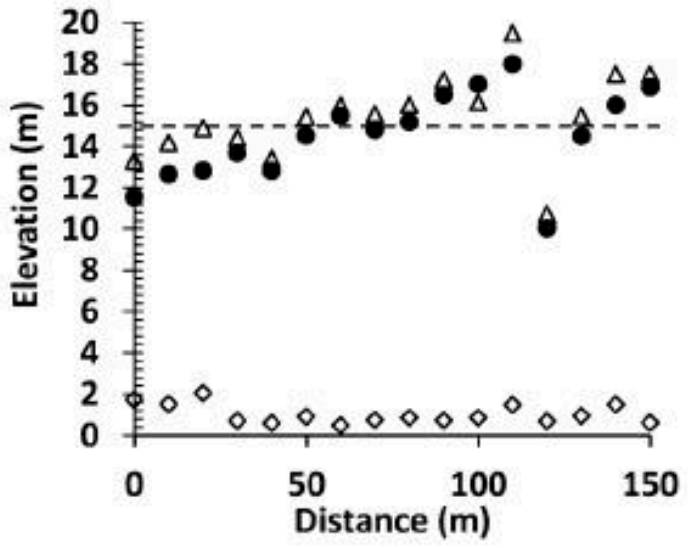

(b)
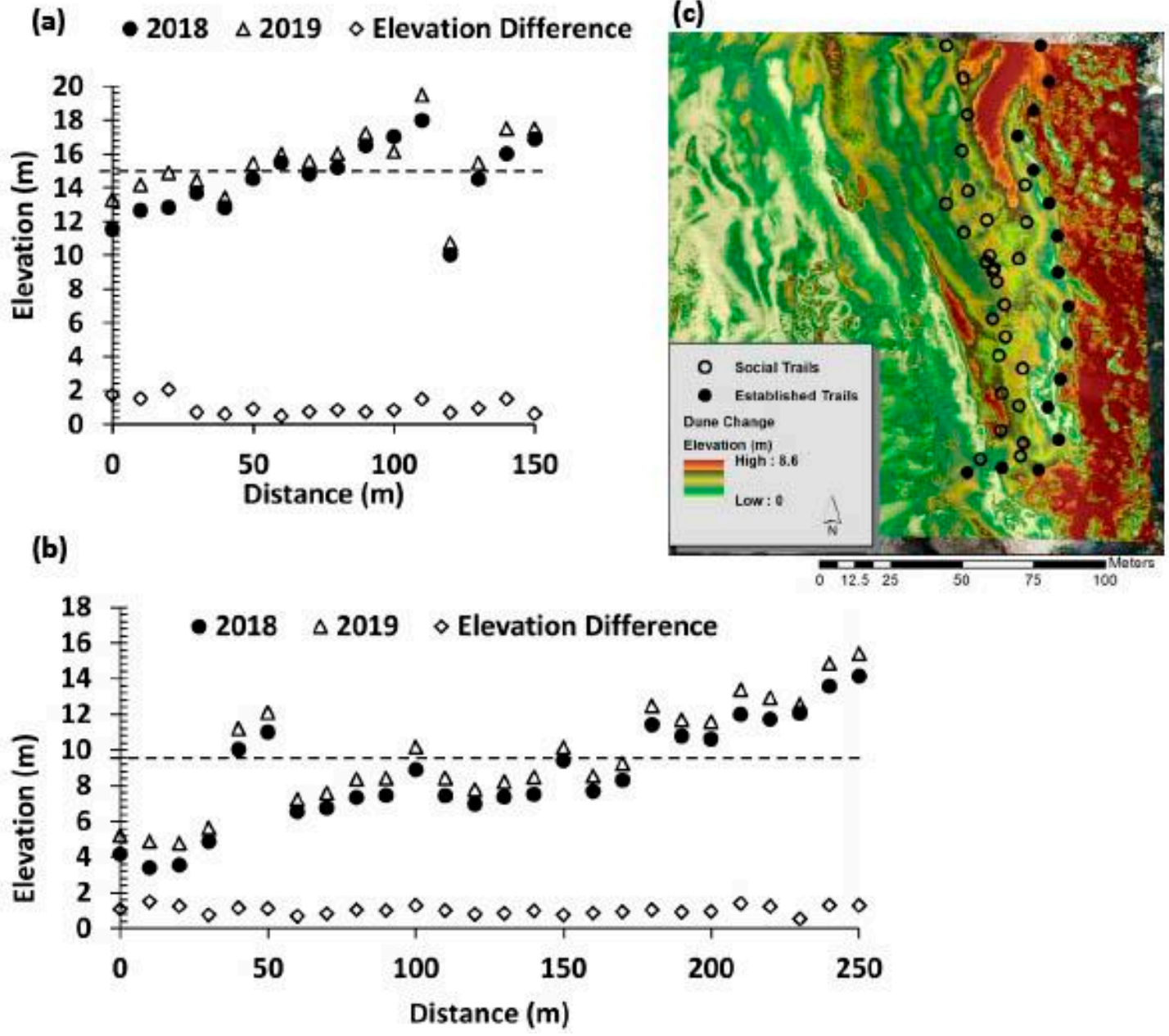

Figure 6. Comparison of elevation changes for the established trails (a) and social trails (b) extracted from registered 0.12-m digital elevation model (DEMs) from 2018 to 2019 along 10-m intervals. The trails were selected backdunes where the start and end points were in proximity to each other (c). The mean elevation change was given in a dash line.

\subsection{Erosion and Deposition Classification}

The model was able to predict areas of erosion and deposition. The resulting elevation changes have negative pixel values representing erosion and positive pixel values representing deposition. The mean elevation change determined by zonal statistics revealed that the pixels classified as deposition had almost twice the amount of elevation gain when compared to erosion (Table 1).

Table 1. Comparison of pixels classified as erosion area and deposition areas.

\begin{tabular}{cccc}
\hline Map Layer & Area $^{\mathbf{2}}$ & Std. dev. (m) & Mean Elevation Change (m) \\
\hline Erosion & 11,962 & 0.52 & 0.55 \\
Deposition & 18,333 & 0.60 & 0.97 \\
\hline
\end{tabular}

The decision tree model shows where the erosion and deposition areas formed within the study sites in relation to the vegetation density, slope, and aspect parameters (Figure 7). The eroded areas were patchy across the study area. 


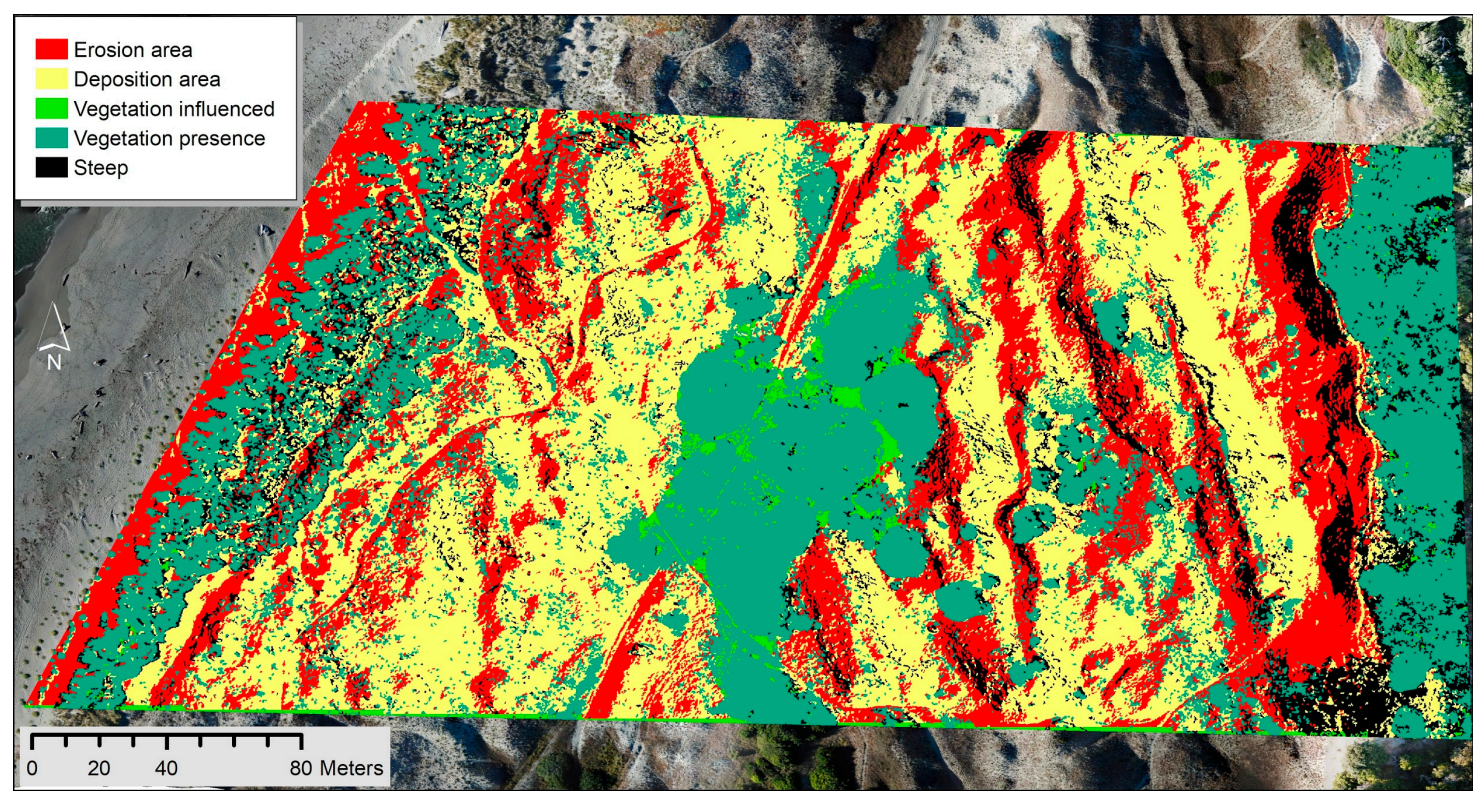

Figure 7. Map of results from the decision tree. Yellow shows the areas of potential gain of elevation, while the red shows areas of possible erosion.

\subsection{Invasive Species Classification}

Due to technological difficulties with the KAP camera and additional issues such as adverse wind conditions and limited trail access, the NIR camera was decommissioned halfway through the data collection process. This resulted in a smaller area being covered with the NIR camera, compared to the larger area covered by the RGB camera (Figure 8A), which was collecting data for a longer period of time. The larger area covered by the RGB camera was used separately without the NIR bands for a supervised vegetation classification based on the "maximum likelihood classification" method (Figure 8B). Based on the accuracy assessment, the supervised classification using just the RGB bands provided a decent classification (Table 2), however, it was not as accurate as the supervised "maximum likelihood" classification that incorporated the NDVI of the smaller NIR study site (Figure 8C). 


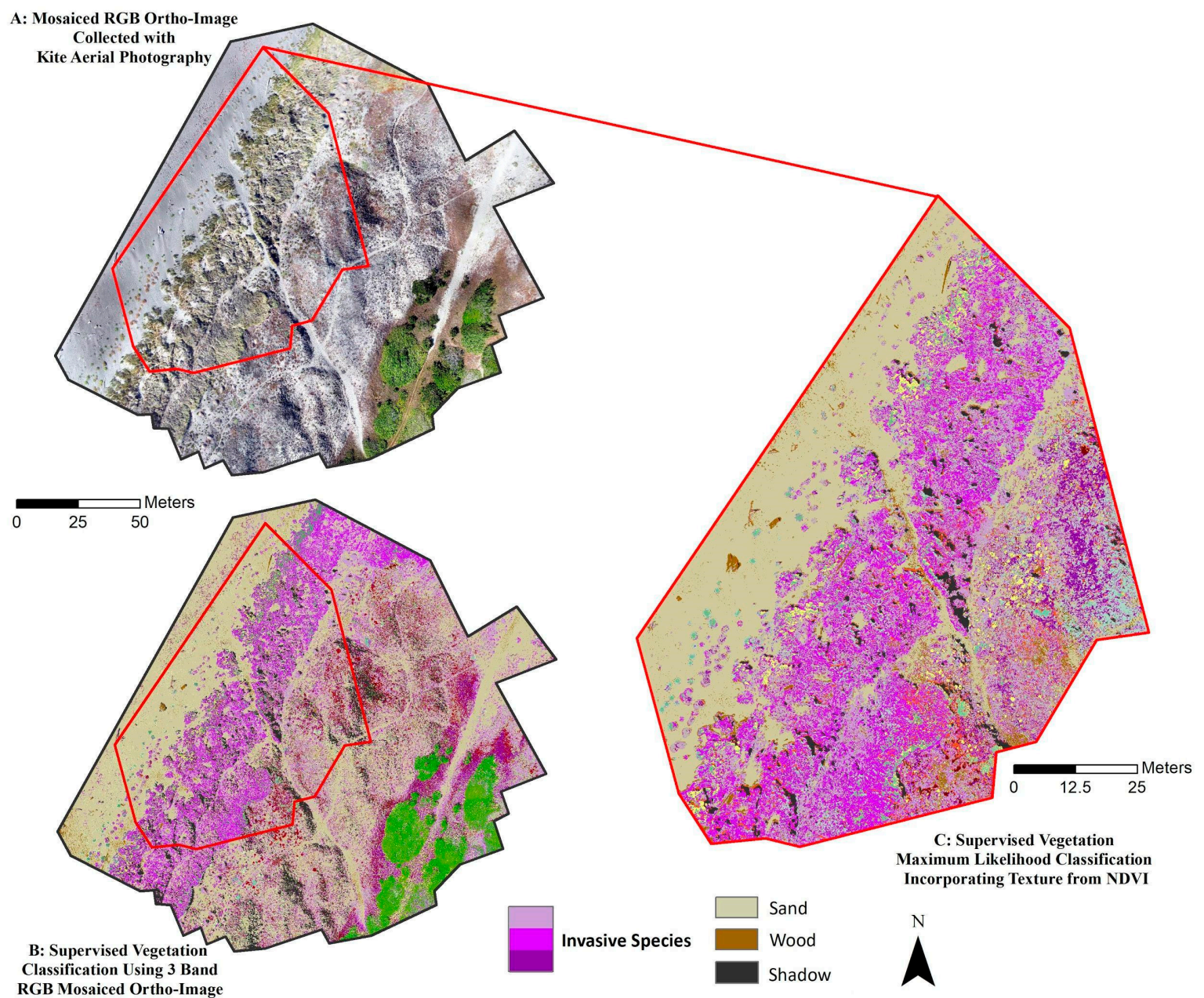

Figure 8. UAV imagery shows the study area in the Manila Dunes (A) and compares the results of pixel-based supervised maximum likelihood vegetation classification using only RGB orthoimage (B) with the results of same supervised classification methods; however, incorporating a NIR band and texture from the normalized difference vegetation index (NDVI) (C). The green features in Figure 8B are mixed conifer forest, and the purple features are invasive mat vegetation.

Table 2. Supervised classification accuracy assessment on the normalized difference vegetation index (NDVI) NIR image and the RGB image.

\begin{tabular}{cccc}
\hline Image & No. of Random Points & Correctly Identified & Percent Accurate \\
\hline NIR/RGB composite image & 130 & 75 & $58 \%$ \\
Only using RGB image & 160 & 86 & $54 \%$ \\
\hline
\end{tabular}

We mapped the dominant invasive/native species and major land-use/cover types within a subplot of dune habitats using the object-based image analysis techniques (Figure 9). Of the species, European beach grass, ice plant, and European sea rocket were the leading invasive species, while toyon, buckwheat, and coyote brush were the dominant native species (Figure 9). European beach grass outcompetes other species and is widely distributed across the dunes. 


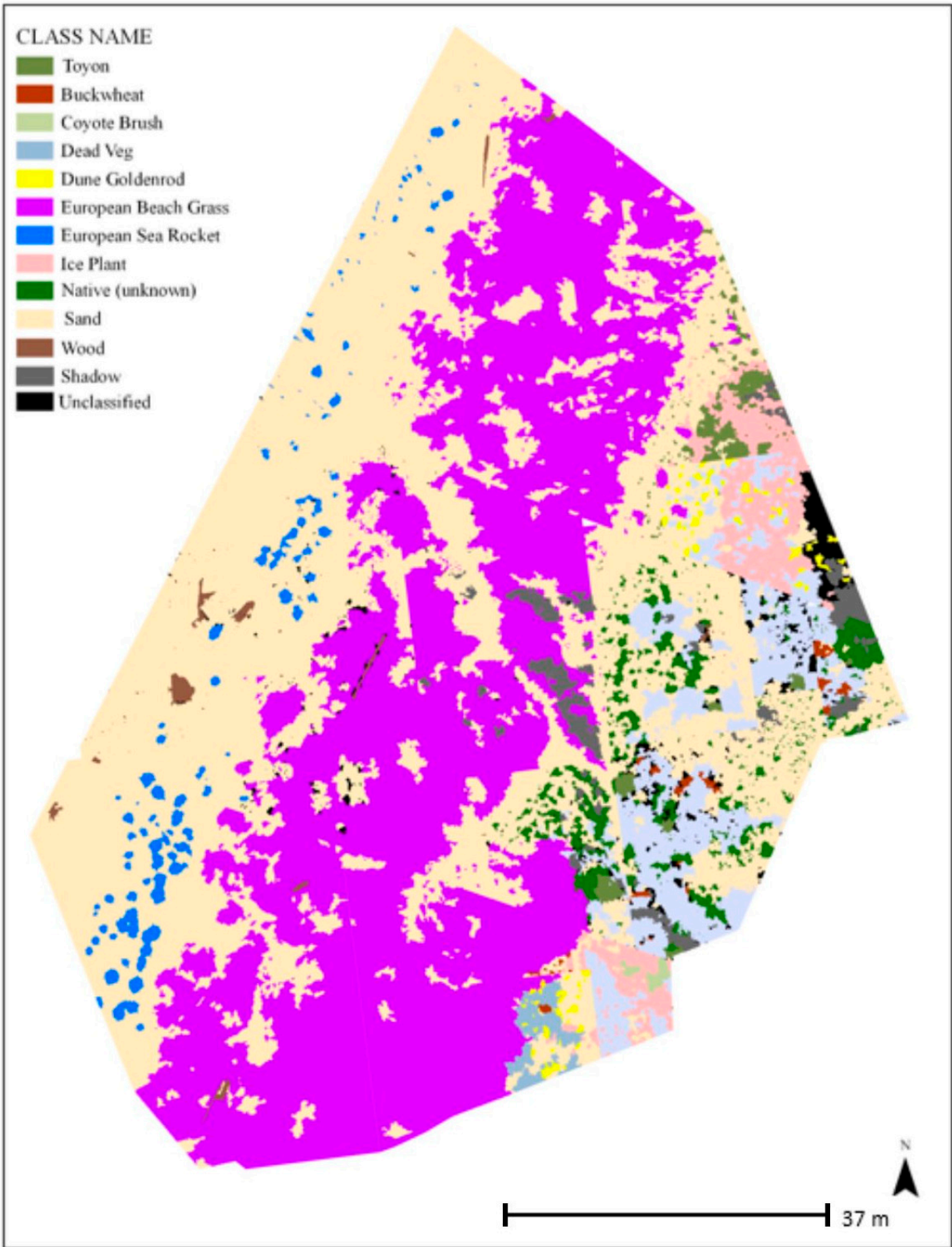

Figure 9. Results of the species classification using the feature extraction tool in ENVI ${ }^{\circledR}$.

\section{Discussion}

This study describes a new approach to coastal dune mapping, with the use of both UAV photogrammetry and KAP. We had limited the flights to a small plot at the FOD premise due to permission constraints of UAV flights at the border of the Bureau of Land Management (Northern Humboldt Bay) and private properties at the Southern Humboldt Bay. The study area is a part of the Manila Dunes, which extend $9.6 \mathrm{~km}$. The vegetation and dune morphodynamics are fairly homogenous across the landscape, and therefore, our findings and methodology are applicable for monitoring wider areas of Humboldt Bay. We found the presence of invasive species, vegetation density, and established trails contribute to the stabilizing of dunes.

Decision trees similar to the one constructed for this study are useful across various fields of study, such as: determining age structures of heathland vegetation [26], mapping fragmented sand dunes landscapes [27], and habitat type classifications [28]. With the use of both RGB imagery and RGB-NIR imagery, we were able to include vegetation vigor in our analysis of vegetative cover. For example, 
Mbolambi [29] performed a decision tree classification using the Red and NIR multispectral bands for delineating habitat conditions of vegetation (i.e., intact vegetation, alien vegetation, and degraded vegetation). The dune movement estimates from the erosion deposition classification indicated fewer areas of erosion than deposition. This erosion and deposition predictive decision tree model was able to provide an estimate of the dune movements while considering additional environmental factors such as the vegetative cover, wind direction, and social trails.

High-resolution DSM derived through UAV and Lidar are widely used for detecting sand dune migrations [30,31], elevation changes [5,32], and coastal erosion [5]. However, it is challenging using two different sensors (for example, UAV and Lidar) for estimating dune migrations due to varying spatial and spectral resolutions, which need intensive geospatial processing for co-registration, resampling, and preprocessing. Therefore, this study used two UAV imageries acquired in 2018 and 2019 in September with fairly even spatial resolutions. Our dune migration results are useful to monitor the area for coastal erosion, and the methodology can be applied for a large area of Humboldt Bay using Lidar data. The UAV data was limited to a small area due to permission issues from the landowners, FAA permitting issues, and limited battery life for longer flights.

Coastal sand dunes are constantly shifting due to coastal erosion and the continual movement of the dunes by the wind [33-35]. Wind direction data with a higher spatial resolution may give us more site-specific data that could benefit in further research for a wider area. This study did not use wind data for the analysis (Figure 4), but we observed 12 MERRA-2 images to find the historical wind directional data to delineate the aspect direction for the model. Furthermore, wind data provides a general indication of the average wind conditions in the region, which relates with the tidal influences on this coastal region.

When looking at dune movements seen around the two different trails, social and established, the dunes around the established trails were more stable (located at comparatively higher elevations along the ridge) and did not move as much as the dunes near social trails within the one-year period of this analysis (Figure 3). The differences between the stability of the two trails could be a combination of identified factors: that the established trails were planned and created with the location and site stability in mind and that social trails can be found in places that have lower elevation paths, where users can easily make the shortcut to the beach without hiking. RGB data covers a larger area; using only the RGB bands results in a less accurate classification compared to the texture analysis classification, which incorporates both the NIR and RGB bands. Since a NIR band is necessary to calculate the NDVI, the smaller study site covered by the NIR provides a more accurate classification by incorporating spectral and vegetation textures into the classification.

Supervised classification distinguished between sand and vegetation, though not necessarily different types of vegetation (Figure 6). High dimensionality of dune habitats creates a salt and pepper effect resulting from traditional pixel-based image classification [36]. For example, Madurapperuma et al. [3] received a lower accuracy for beach grass and sand land-use classes due to the high microtopographic variation of the dune ecosystem. We were able to acquire adequate ground reference points (130 points) using geotagged photos to map native/invasive species distributions.

High-resolution UAV and KAP data were useful to capture microtopographical variations of the dune habitats, accounting for the high spatial and temporal resolutions. Although the KAP images acquired for a subplot of the main study area would be useful to have four bands (RGB and NIR), especially for the vegetation analysis, KAP is very reliable for coastal mapping, especially for developing countries, with the advantages of low costs, high resolutions, limited regulations, and easy flying during high wind velocities [7,37]. Understanding where dune erosion is emerging and being able to map invasive/native species habitats is crucial for the FOD in order to implement the best land management practices and meet their goals of the ecological restoration of native plant habitats, controlling invasive plant populations, and the conservation and preservation of the coastal land. 


\section{Conclusions}

Developing a long-term monitoring program will aid land stewardship and restoration efforts by the Friends of the Dunes Land Trust. Finally, a developed workflow for an expedited and accessible land cover classification method can be applied to any type of imagery with a variety of management goals in mind. Using aerial imagery collected with low-cost consumer-grade UAV, our goal was to estimate dune movements in relation to trails, vegetation, and topographical factors. In addition, we mapped the invasive species habitats, which is useful for the FOD land trust managers to implement the best land management practices via the ecological restoration of native plant habitats and controlling invasive plant populations.

Social trails have arisen from lower elevation areas than established trails, which make the ecosystem fragile and vulnerable to the trampling of native plant habitats. This indicates that there may be a greater amount of dune movements along the social trails than the established trails. This information could be used by the FOD to further educate visitors on the impacts of social trails on dune habitats while also helping inform the FOD of where the expansion of established trails may be viable and less intrusive to the ecosystem. With the use of the decision tree, we were able to determine areas that are more likely to experience erosion (elevation loss) and sediment deposition (elevation gain). Utilizing this method may be useful for future planning decisions due to the ability to determine the erosion and deposition risks that could have an effect on the infrastructures installed on FOD property. This information could be vitally important to the FOD in the implementation of conservation plans. The variety of small, mixed vegetation types throughout the dunes causes difficulties in classifying individual plant types when using object-based methods. Object-based image classification works the best when the features to be identified have distinct shapes, i.e., sparse dune mat invasive/native vegetation throughout the landscape.

Author Contributions: The author contributions are as follows: conceptualization, B.M. (Buddhika Madurapperuma); UAV data acquiring, J.L.; KAP data preprocessing, M.M.; decision tree analysis, B.M. (Brian Murphy); data processing, J.M.; objected-based image analysis, K.D.; writing, C.S.; supervised classification, S.M. (Sam MacAdam); classification, S.M. (Sierra Monroe); writing-review and editing, L.C. and S.M. (Shayne Magstadt); KAP data acquiring, J.D. and S.M. (Solveig Mitchell); review and editing. All authors have read and agreed to the published version of the manuscript.

Funding: This research received no external funding.

Acknowledgments: James Lamping, an FAA Certified Remote Pilot, flew the UAV under FAA regulations and with permission from the HSU Unmanned Aircraft System (UAS) Review Committee and the Friends of the Dunes Land Trust. The authors gratefully acknowledge the 2018 students from the intermediate remote sensing class at Humboldt State University, who collected the geospatial data for this study.

Conflicts of Interest: The authors declare no conflicts of interest.

\section{References}

1. Shanmugam, S.; Lucas, N.; Phipps, P.; Richards, A.; Barnsley, M. Assessment of Remote Sensing Techniques for Habitat Mapping in Coastal Dune Ecosystems. J. Coast. Res. 2003, 19, 64-75.

2. Adão, T.; Hruška, J.; Pádua, L.; Bessa, J.; Peres, E.; Morais, R.; Sousa, J. Hyperspectral Imaging: A Review on UAV-Based Sensors, Data Processing and Applications for Agriculture and Forestry. Remote Sens. 2017, 9, 1110. [CrossRef]

3. Madurapperuma, B.; Close, P.; Fleming, S.; Collin, M.; Thuresson, K.; Lamping, J.; Dellysse, J.; Cortenbach, J. Habitat mapping of Ma-le'1 Dunes coupling with UAV and NAIP imagery. Proceedings 2018, 2, 368. [CrossRef]

4. Laporte-Fauret, Q.; Marieu, V.; Castelle, B.; Michalet, R.; Bujan, S.; Rosebery, D. Low-Cost UAV for high-resolution and large-scale coastal dune change monitoring using photogrammetry. J. Mar. Sci. Eng. 2019, 7, 63. [CrossRef]

5. Pagán, J.I.; Bañón, L.; López, I.; Bañón, C.; Aragonés, L. Monitoring the dune-beach system of Guardamar del Segura (Spain) using UAV, SfM and GIS techniques. Sci. Total Environ. 2019, 687, 1034-1045. [CrossRef] 
6. De Giglio, M.; Greggio, N.; Goffo, F.; Merloni, N.; Dubbini, M.; Barbarella, M. Comparison of Pixel-and Object-Based Classification Methods of Unmanned Aerial Vehicle Data Applied to Coastal Dune Vegetation Communities: Casal Borsetti Case Study. Remote Sens. 2019, 11, 1416. [CrossRef]

7. Madurapperuma, B.D.; Dellysse, J.E. Coastal fringe habitat monitoring using Kite Aerial Photography: A Remote Sensing-based case study. J. Trop. For. Environ. 2018, 8. [CrossRef]

8. Archibald, D. The Story of the Earth's Atmosphere, 3rd ed.; George Newnes Ltd.: London, UK, 1897; p. 174.

9. Madurapperuma, B.; Barger, J.; Collin, M.; Emerson, C.; Fleming, S.; Murphy, B.A. Geospatial recipe for identifying social values and fragmentation issues of the Friends of the Dunes Land Trust. Humboldt. J. Soc. Relat. 2019, 1, 8-21.

10. Friends of the Dunes. Coastal Development PERMIT application Notice. 2015. Available online: http: //www.friendsofthedunes.org/nature-center/FOD_CDP_Application_5_19_15\%20WEB.pdf (accessed on 25 October 2018).

11. Marion, J.L.; Leung, Y.-F.; Nepal, S.K. Monitoring trail conditions: New methodological considerations. George Wright Forum 2006, 23, 36-49.

12. Lamping, J.; Murphy, B.; McFarland, J.; Porteous, Z.; Smith, C.; Monroe, S.; Kennedy, J.; MacAdam, S.; Bueche, S.; Becker, R.; et al. UAV photogrammetry for surveying dune habitats: A review of research needs of the Friends of the Dunes Land Trust. In Proceedings of the INRSEP/CNRS UG Scientific Research Symposium, Arcata, CA, USA, 28 September 2018.

13. Del Vecchio, S.; Prisco, I.; Acosta, A.T.; Stanisci, A. Changes in plant species composition of coastal dune habitats over a 20-year period. AoB Plants 2015, 7. [CrossRef]

14. Leung, Y.; Newburger, T.; Jones, M.; Kuhn, B.; Woiderski, B. Developing a Monitoring Protocol for Visitor-Created Informal Trails in Yosemite National Park, USA. Environ. Manag. 2010, 47, 93-106. [CrossRef] [PubMed]

15. Moreno-Casasola, P. Sand Movement as a Factor in the Distribution of Plant Communities in a Coastal Dune System. Vegetation 1986, 65, 67-76. [CrossRef]

16. Sloss, C.R.; Shepherd, M.; Hesp, P. Coastal Dunes: Geomorphology. Nat. Educ. Knowl. 2012, 3, 2.

17. Effat, H.A.; Hegazy, M.; Behr, F.J. Cartographic modelling of potential sand dunes movement risk using remote sensing and geographic information systems in Sinai, Egypt. In Applied Geoinformatics for Society and Environment, I, 2nd ed.; Stuttgart University of Applied Sciences: Karlsruhe, Germany, 2012; pp. 139-148.

18. Hesp, P.A.; Davidson-Arnott, R.; Walker, I.J.; Ollerhead, J. Flow dynamics over a Foredune at Prince Edward Island, Canada. Geomorphology 2005, 65, 71-84. [CrossRef]

19. Friends of the Dunes. Public Access Trail Plan for the Friends of the Dunes; Humboldt Coastal Nature Center, Friends of the Dunes: Arcata, CA, USA, 2010; pp. 1-32.

20. Leppig, G.; Pickart, A. Vascular Plants of Humboldt Bay's Dunes and Wetlands; U.S Fish and Wildlife Service and California Department of Fish Game, 2014; pp. 1-24. Available online: www.fws.gov/refuge/humboldt_bay/ (accessed on 21 March 2020).

21. Pickart, A. Site Summary and Preserve Design, Lanphere-Christensen Dunes Preserve, the Nature Conservancy; On file at the Lanphere Unit of the USFWS Humboldt Bay Wildlife Refuge; Friends of the Dunes: Arcata, CA, USA, 1987; 29p.

22. Bryson, M.; Duce, S.; Harris, D.; Webster, J.M.; Thompson, A.; Vila-Concejo, A.; Williams, S.B. Geomorphic changes of a coral shingle cay measured using kite aerial photography. Geomorphology 2016, 270, 1-8. [CrossRef]

23. Ghadiry, M.; Shalaby, A.; Koch, B. A new GIS-based model for automated extraction of Sand Dune encroachment case study: Dakhla Oases, western desert of Egypt. Egypt. J. Remote Sens. Space Sci. 2012, 15, 53-65. [CrossRef]

24. Al-Hashemi, H.M.B.; Al-Amoudi, O.S.B. A review on the angle of repose of granular materials. Powder Technol. 2018, 330, 397-417. [CrossRef]

25. Srinivasan, G.N.; Shobha, G. Statistical texture analysis. Proc. World Acad. Sci. Eng. 2008, 36, $1264-1269$.

26. Delalieux, S.; Somers, B.; Haest, B.; Spanhove, T.; Vanden Borre, J.; Mücher, C.A.; Vanden Borre, J.; Mücher, C.A. Heathland conservation status mapping through integration of hyperspectral mixture analysis and decision tree classifiers. Remote Sens. Environ. 2012, 126, 222-231. [CrossRef] 
27. Marzialetti, F.; Giulio, S.; Malavasi, M.; Sperandii, M.G.; Acosta, A.T.R.; Carranza, M.L. Capturing coastal dune natural vegetation types using a phenology-based mapping approach: The potential of Sentinel-2. Remote Sens. 2019, 11, 1506. [CrossRef]

28. Mücher, C.A.; Kooistra, L.; Vermeulen, M.; Vanden Borre, J.; Haest, B.; Haveman, R. Quantifying structure of Natura 2000 heathland habitats using spectral mixture analysis and segmentation techniques on hyperspectral imagery. Ecol. Indic. 2013, 33, 71-81. [CrossRef]

29. Mbolambi, C. Assessment of Coastal Vegetation Degradation Using Remote Sensing in False Bay, South Africa. Ph.D. Thesis, Stellenbosch University, Stellenbosch, South Africa, 2016.

30. Xia, J.; Dong, P. A GIS add-in for automated measurement of sand dune migration using LiDAR-derived multitemporal and high-resolution digital elevation models. Geosphere 2016, 12, 1316-1322. [CrossRef]

31. Ayoub, F.; Bridges, N.T.; Avouac, J.P.; Leprince, S.; Lucas, A. Measuring sand flux and its seasonality from a time series of HiRISE images. In Proceedings of the Third International Planetary Dunes Workshop: Remote Sensing and Data Analysis of Planetary Dunes, Flagstaff, AZ, USA, 12-15 June 2012; Volume 1673, pp. 1-2.

32. Moloney, J.G.; Hilton, M.J.; Sirguey, P.; Simons-Smith, T. Coastal Dune Surveying Using a Low-Cost Remotely Piloted Aerial System (RPAS). J. Coast. Res. 2018, 34, 1244-1255. [CrossRef]

33. Łabuz, T.A. Coastal dunes: Changes of their perception and environmental management. In Environmental Management and Governance; Springer: Cham, Switzerland, 2015; pp. 323-410.

34. Mitasova, H.; Overton, M.; Harmon, R.S. Geospatial analysis of a coastal sand dune field evolution: Jockeys Ridge, North Carolina. Geomorphology 2005, 72, 204-221. [CrossRef]

35. Mull, J.; Ruggiero, P. Estimating storm-induced dune erosion and overtopping along U.S. West Coast Beaches. J. Coast. Res. 2014, 30, 1173-1187. [CrossRef]

36. Yu, Q.; Gong, P.; Clinton, N.; Biging, G.; Kelly, M.; Schirokauer, D. Object-based detailed vegetation classification with airborne high spatial resolution remote sensing imagery. Photogramm. Eng. Remote Sens. 2006, 72, 799-811. [CrossRef]

37. Madurapperuma, B.D.; Dellysse, J.E.; Zahir, I.L.M.; Aathamlebbe, I. Mapping shoreline vulnerabilities using kite aerial photographs at Oluvil Harbour in Ampara. In Proceedings of the 7th International Conference of South Eastern University of Sri Lanka, Oluvil, Sri Lanka, 7-8 December 2017; pp. 197-204.

(C) 2020 by the authors. Licensee MDPI, Basel, Switzerland. This article is an open access article distributed under the terms and conditions of the Creative Commons Attribution (CC BY) license (http://creativecommons.org/licenses/by/4.0/). 